\title{
Seat to Head Transmissibility during Exposure to Vertical Seat Vibration: Effects of Posture and Vibration Magnitude
}

\author{
Mahesh K. Bhiwapurkar \\ Mechanical Engineering Department, O. P. Jindal University, Raigarh, Chhattisgarh-496001, India.
}

\author{
V. H. Saran and Suraj P. Harsha \\ Noise and Vibration Control Lab, Mechanical and Industrial Engineering Department, Indian Institute of Tech- \\ nology Roorkee, Roorkee-247667, India.
}

\begin{abstract}
(Received 7 July 2015; accepted 5 October 2016)
The low frequency vibration transmitted to the body can affect the comfort, performance, and health of humans. In this paper, the effect of variations in posture and vibration magnitude on the head motion in three translational axes (fore-and-aft, lateral and vertical) has been studied with a vertical seat vibration. Thirty healthy male subjects were exposed to random vibration with three vibration magnitudes of $0.4,0.8$, and $1.2 \mathrm{~m} / \mathrm{s}^{2} \mathrm{rms}$ over the frequency range of 1-20 Hz. The results are analysed in terms of seat-to-head-transmissibility (STHT) for the head motions in two seated postures (backrest and leaning forward on table). The measurement of the head motion was made with an apparatus (bite-bar) specifically developed for this purpose. The measured responses to a single axis seat vibration have also shown notable cross-axis responses in both vertical and fore-and-aft axes for both postures. The crossaxis fore-aft and vertical STHT responses showed single peak near $5 \mathrm{~Hz}$ in both postures. An increasing intensity of vibration yields a non-linear softening effect in the muscle tension, particularly in the presence of back support, however, the body stiffens under a greater upper body motion in the forward leaning posture. The combined effect of the unsupported back and hands support was observed to be more pronounced around the resonance peak in the forward lean posture.
\end{abstract}

\section{INTRODUCTION}

The effect of vertical seat vibration on the human body is the most investigated topic in biodynamics. The effect of many variables (e.g., vibration magnitudes, seat condition, posture, and frequency) and the effect on numerous variables (e.g., transmissibility, comfort, task performance, vibration performance, etc.) have been well documented. Many experimental studies report consistent findings for the vertical response of the seated human body exposed to whole-body vertical vibration. A primary resonance has been found between 4 and $6 \mathrm{~Hz}$ in STHT responses. ${ }^{1-8}$ A second resonance has been found between 8 and $12 \mathrm{~Hz}$ in some investigations, ${ }^{5,7}$ but it is less dominant. A few studies were cited in which vibration at the seat occurred in other axes of head motion. It was reported that the fore-and-aft head motion was affected by the vertical position on the head and vice-versa. ${ }^{9}$ The range of idealized values of driving-point mechanical impedance and the apparent mass of seated occupants exposed to vertical vibration, defined in ISO 5982 (2001), is considered applicable only for an erect sitting posture with no back support. ${ }^{10}$

The effect of vibration magnitude on the transmission of seat vibration to the head has been studied by many researchers in an attempt to explain whether the human body behaves in a linear or a nonlinear manner. Griffin et al. investigated the effect of seat vibration magnitude on motion transmitted to the head, varying in seven equal-magnitude increments from $0.4 \mathrm{~m} / \mathrm{s}^{2}$ to
$2.8 \mathrm{~m} / \mathrm{s}^{2}$ rms. ${ }^{11}$ It was pointed out that the effect was smaller than the variation found within and between individuals. Hinz and Seidel reported a decrease in STHT resonance frequency from 5 to $3.8 \mathrm{~Hz}$, when the vibration was increased from 1.5 to $3.0 \mathrm{~m} / \mathrm{s}^{2} \mathrm{rms}^{4}$

The effect of the sitting posture on the biodynamic response has been a complex issue. The differences in the body postural variations result in considerable variability of the ${ }^{12}$ measured biodynamic data. It has been shown that the type of backrest on a seat can affect the level of vibration reaching the head ${ }^{13-15}$ and that the effect is dependent on the axis of vibration of the seat. ${ }^{16}$ Coermann investigated the effect of two body postures, relaxed and erect, on vertical STHT. ${ }^{1}$ The results revealed that a relaxed posture transmitted more motion to the head for frequencies below about $5 \mathrm{~Hz}$, and substantially more head motion occurred with the subject sitting in an erect posture for frequencies between $5 \mathrm{~Hz}$ and $20 \mathrm{~Hz}$. A slight increase in resonance frequency from $4.5 \mathrm{~Hz}$ to $5.2 \mathrm{~Hz}$ was observed when the posture ${ }^{17}$ changed from relaxed to erect. Griffin ${ }^{17}$ examined the effect of eight sitting postures ranging from erect to slouched on the transmission of vertical vibration from the seat to the head. An erect body posture increased transmissibility at all frequencies above $3 \mathrm{~Hz}$ with approximately a fourfold increase in the range of 15 to $25 \mathrm{~Hz}$ and unity at $25 \mathrm{~Hz}$, whilst the transmissibility in the slouched posture found below unity above $3 \mathrm{~Hz}$. The authors however, express doubts about whether the 
vibration inputs measured in the field would produce the same effects on comfort, performance, and health, as those determined in the laboratory.

However, there is an absence in the data results for the forward-lean posture with the hands on the table, which is common practice for a passenger performing reading and writing activities while riding on a train. Understanding the mechanical responses of the body in this posture is essential in order to assist in reducing vibration's undesirable influences on the health, the activities and the feelings of occupants. This study is focused on the transmission of vertical seat vibration to the head in each of the three translational axes (fore-and-aft, lateral, and vertical). The study also investigates the effect of sitting postures and vibration magnitudes on STHT response.

The vibration magnitudes and postures that are relevant for train passengers performing sedentary activities are chosen. ${ }^{18}$ This experimental study is useful in vehicle seat design and biodynamic study of the human body under low-frequency vibration. It was hypothesized that the resonance peak and the resonance frequency of the transmissibility would decrease with increases in vibration magnitude, but that the extent of the decrease would vary with posture. From the study, ${ }^{11}$ it was observed that the effect of the head- pointing angle did not affect motion transmitted to the head above about $30 \mathrm{~Hz}$ during vertical whole body vibration (WBV). Therefore, the effect of the head angle is not considered in the present study.

\section{SUBJECTS AND METHODS}

\subsection{Subjects and Subject Postures}

Thirty healthy male subjects, with a mean age of 22.91 years (standard deviation [SD] 4.58 years, a mean mass of $72.06 \mathrm{~kg}$ (SD $12.04 \mathrm{~kg}$ ), and a mean stature of $173.87 \mathrm{~cm}(\mathrm{SD} 5.86 \mathrm{~cm})$ participated voluntarily in the experiment under informed written consent and were given a small remuneration. A few studies have shown that significant effects in the physical characteristics of subjects occurred if there was a large variation in age, height, and weight among subjects. ${ }^{11,13,14}$ Therefore, the present study uses numerous subjects within the same age group to avoid the effect of inter-subject variability and subjective characteristics.

The subjects had no history of back pain. Each subject was informed about the purpose of the study and the experimental setup. The experiment was approved by the Institutional Human Ethics Committee. Each subject was exposed to six different combinations of vibration magnitudes $(0.4,0.8$ and $1.2 \mathrm{~m} / \mathrm{s}^{2} \mathrm{rms}$ ) in two sitting postures, representing a passengerlike sitting posture: (i) Backrest posture: the subject is seated with a backrest support and with hands in lap. (ii) Forwardlean posture: the seated subject leans forward 20 degrees, with hands placed on the table.

\subsection{Experimental Setup}

A schematic representation of the experimental setup used for biodynamic response study is shown in Fig. 2. The study is conducted on the vibration simulator developed as a mockup of a railway vehicle, housed in a partially soundproof

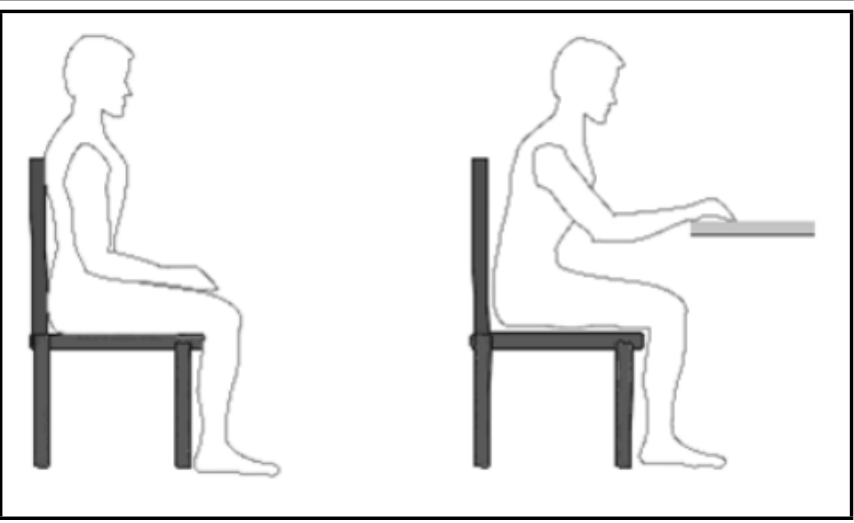

Figure 1. Subject sitting posture with backrest and with hands on lap (a), and forward-lean posture with hands on table (b).

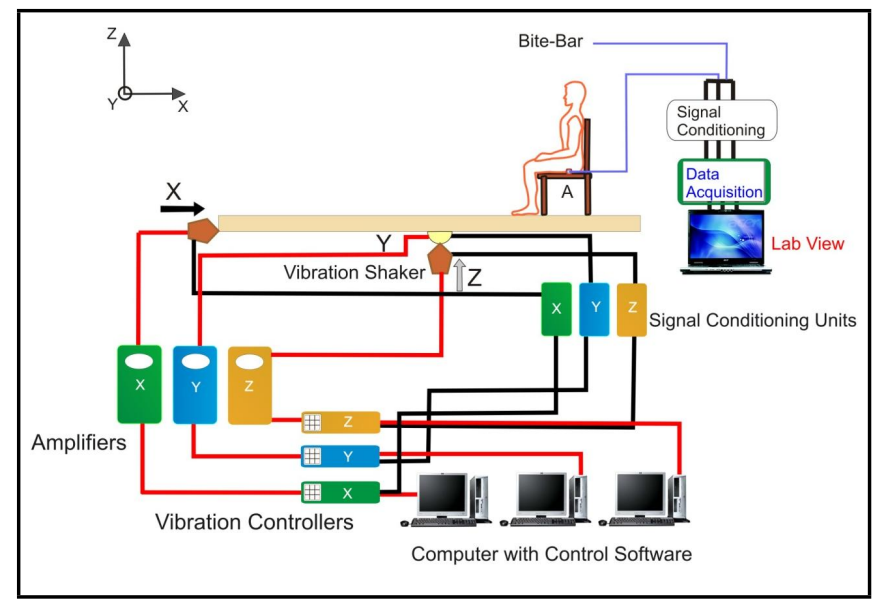

Figure 2. Schematic representation of laboratory set up.

room. ${ }^{19,20}$ It consists of a platform of $2 \mathrm{~m} \times 2 \mathrm{~m}$, fabricated from a material of aluminium alloy frame with thick steel plates at 6 the top and bottom, to which the three exciter pushrods are bolted via ball joints. The platform incorporates a table and chairs with rigid wooden seats securely fixed. The backrest of the chair is rigid, flat, and vertical. None of the seats, backrests, or tables had any resonances within the frequency range studied (up to $20 \mathrm{~Hz}$ ) in any of the three axes. The weight of the platform is supported by four helical springs placed under each corner.

Three electrodynamic vibration shakers with vibration controllers are used to provide sinusoidal or random vibration stimuli to the platform in three axes: fore-and-aft (X-axis), lateral (Y-axis), and vertical (Z-axis). Each exciter had a feedback accelerometer by which the controller could fine-tune the drive signal. This allowed for control of the vibrations and automatic shutdown by the control system if the magnitudes fell outside the desired range.

Each vibration exciter can generate Gaussian random vibration. For monitoring purposes, the onboard vibrations of the platform are measured online with a tri-axial accelerometer (PCB 356B41), and the signal is acquired and analysed in the Labview Signal Express software (V3.0, National Instruments) via a signal conditioning unit (ICP 480B21) and a data acquisition system (NI 6218). 


\subsection{Measurement of Head Motion Using Bite Bar}

In the present study, the bite-bar consists of a lightweight, alloy steel strip approximately $21 \mathrm{~cm}$ long, which is screwed on to a U-shaped bite plate made of acrylic material, as shown in Fig. 3. The two accelerometers are mounted at both the ends of the strip at a distance of $10 \mathrm{~cm}$ from the centre of strip. To provide a comfortable and hygienic biting surface, two disposable polyurethane mouthpieces are used above and below the biting surface. The subject holds the bite bar in place by securing the mouthpieces between his teeth. The bite bar is sterilized in a bath of $10 \%$ common chlorine bleach for 10 minutes before use, as per the guidelines in the Manual of Clinical Microbiology. ${ }^{21}$ The design of the present bite bar is similar to that adopted by VanSickle et al. in their study, wherein acceleration at the head was measured. ${ }^{22}$

The bite bar used in the present study weighed about 85 grams, including the weight of the two accelerometers, which are 15 grams each. The lightweight material of the bite bar and the use of miniature accelerometers minimized the possible additional movements acting on the head. Some studies have shown that during whole-body vertical vibration, a variation in the weight of the bite bar of up to 375 grams may have little or no influence on STHT measurements. ${ }^{17}$ It was also shown by Paddan and Griffin that a bite bar which weighed 135 grams had little effect on the measurement of STHT. ${ }^{23}$ Further, this compares favourably with the heavier bite bars used by previous researchers to monitor fewer axes of motion, e.g., 300 grams used by Johnston ${ }^{24}$ and 250 grams used by Barnes and Rance. ${ }^{25}$ The design of the bite bar used in the present study ensured no resonances up to $60 \mathrm{~Hz}$ of the various attachments, which is greater than the frequency of interest.

Out of the two accelerometers, one was used as a dummy to counterbalance the other. The weight contributed by the accelerometers was small (i.e., 15 grams) compared to the total weight of the bite bar (i.e., 85 grams). Also, the total weight of the bite bar was small when compared to the weight of the head, which was around $4.5 \mathrm{~kg}$. The accelerometers were calibrated using a portable vibration calibrator (Model VC 110, PCB Piezotronics INC.) before the start of the experiment.

Since the body may oscillate in several axes during singleaxis excitation of the seat, it is necessary to orient and install accelerometers carefully. The frequency-response characteristic of the bite-bar system is measured under mono-axes random vibration in the frequency range of $1-20 \mathrm{~Hz}$. The results revealed near unity magnitude and a negligible phase in the frequency range of interest.

\subsection{Experimental Seat}

A rigid, flat seat is used in all the experiments carried out to determine the transmission of vibration from seat to head. Rather than using cushioned train seats, chairs with flat seats are used for better vibration transmissibility. If a seat with some form of cushion or foam were used, then the vibration characteristics of this would have been required. The chair consists of a flat wooden board backrest and a seat ( 42 by 42 $\mathrm{cm} 2$ area) fitted on a steel tube frame for sufficient structural

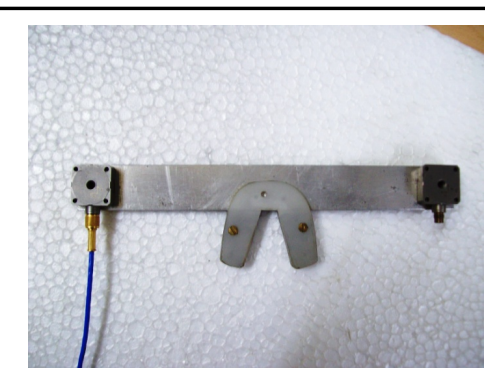

(a)

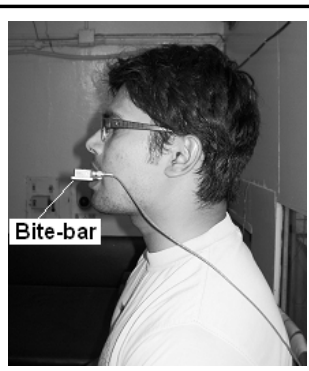

(b)
Figure 3. Instrumented bite bar (a). Instrumented bite bar gripped between teeth by subject (b)

rigidity (Fig. 1). A seat pad accelerometer is placed on the seat surface beneath the subject's ischial tuberosity to measure seat vibration.

\subsection{Vibration Parameters}

The vibration simulator is operated using a computergenerated Gaussian random vibration in a $1 \mathrm{~Hz}$ to $20 \mathrm{~Hz}$ frequency range. Three different levels of vibration magnitudes with overall rms acceleration values of $0.4,0.8$, and $1.2 \mathrm{~m} / \mathrm{s}^{2}$ are presented to the vibration simulator. The acceleration signals from the two tri-axial accelerometers (accelerometer, PCB 356B41) mounted on the bite bar and seat pad are acquired through a multichannel data acquisition (National Instruments) and analysed in the Labview signal express software (V3.0, National Instruments) at 220 samples per second via anti-aliasing filters set at $25 \mathrm{~Hz}$.

The data corresponding to each experimental condition is acquired for a duration of 180 seconds and analysed to determine the STHT phase and their corresponding coherence functions using a $50 \mathrm{~Hz}$ bandwidth with a resolution of $1 \mathrm{~Hz}$. The data analysis corresponding to each trial involves 21 Hanningwindowed averages with an overlap of $75 \%$. In order to account for intra-subject variability, the measurements on each subject were repeated five times and the most repeated value has been considered.

All transfer functions between seat and head motions are calculated by using the cross-spectral density function methods. The transfer function, $H(f)$ is determined as the ratio of the cross-spectral density of seat and head motions, $G_{s h}(f)$ o the power-spectral density of the seat motion, $G_{s s}(f)$. That is, $H(f)=\frac{G_{s h}(f)}{G_{s s}(f)}$.

The coherence between the accelerations was constantly monitored during the experiments. ${ }^{26}$ A measurement was rejected when the coherence value was observed to be below 0.8 within the entire frequency range of interest.

\subsection{Test Procedure}

In order to maintain uniformity and consistency of posture, before starting vibration session, the subjects were asked to sit in a prescribed posture comfortably with full back supported, with upper legs comfortably supported in the seat pan and lower legs oriented vertically. The feet were resting on the floor (vibrating platform), and the subjects were instructed to look straight ahead without any voluntary movement. In 


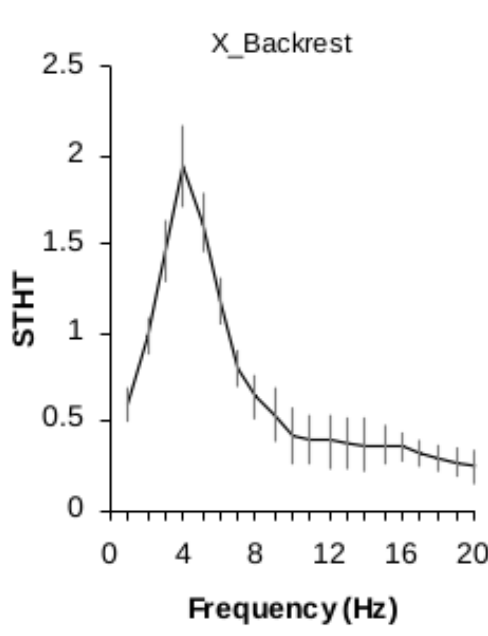

(a)

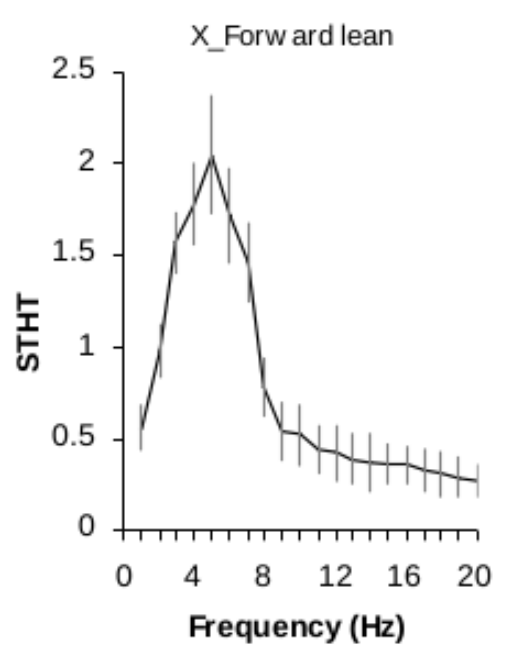

(d)

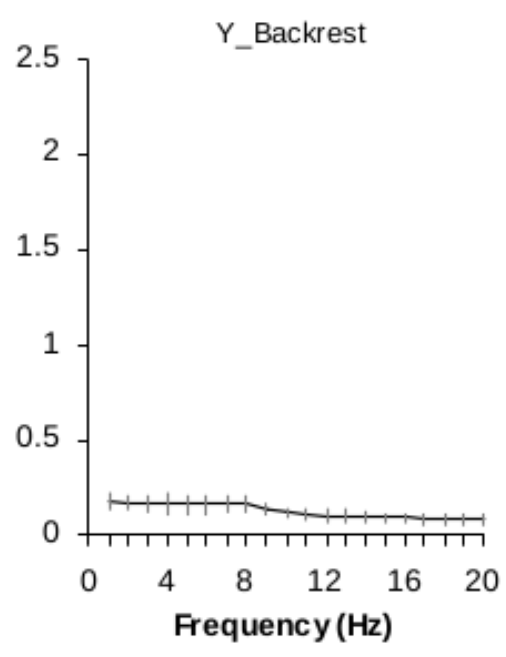

(b)

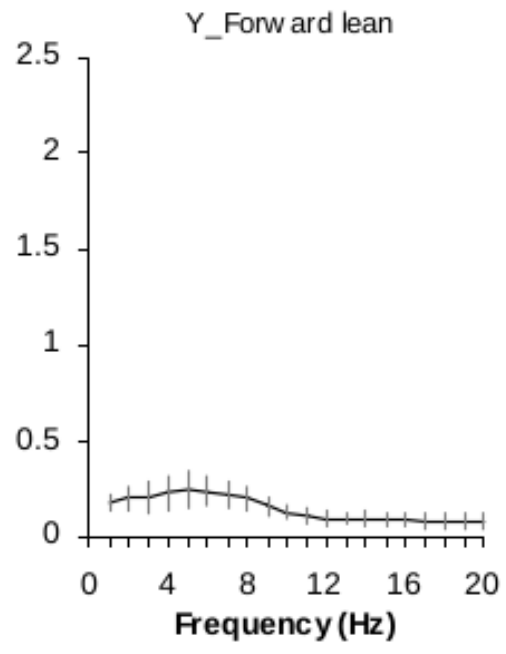

(e)

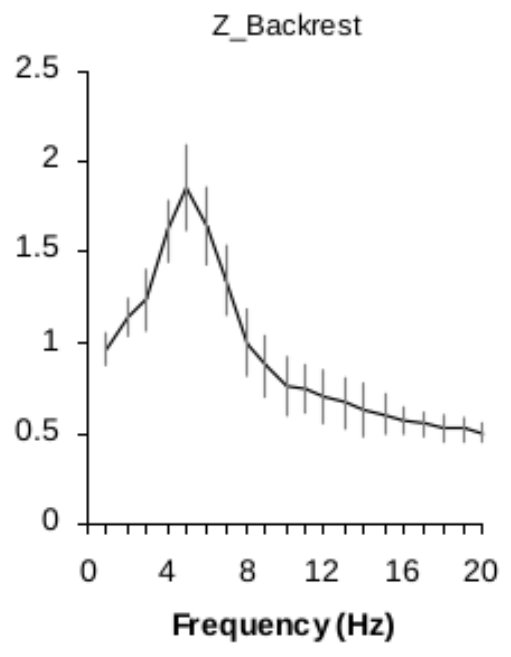

(c)

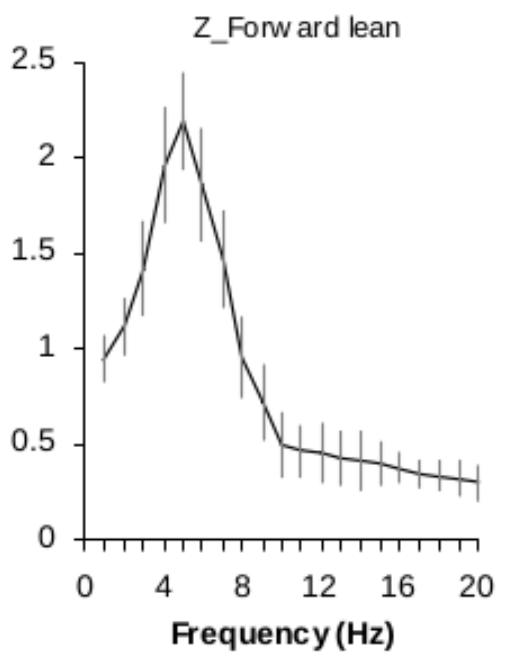

(f)

Figure 4. STHT curve with Z-axis seat vibration at $1.2 \mathrm{~m} / \mathrm{s} 2$ in the backrest posture for head motion on the X-axis (a), Y-axis (b), and Z-axis (c); and the forward-lean posture for head motion in on the X-axis (d), Y-axis (e), and Z-axis (f).

order to maintain the required head posture and reduce voluntary movements of the head, the subjects were instructed to direct their eyes to a cross marked on a stationary wall approximately $1.4 \mathrm{~m}$ away. Meanwhile, the subject's posture during each trial was visually checked by the experimenter to ensure consistency. The subjects were asked to use their teeth to grip a sterilized bite bar. The experimenter made the necessary adjustments to ensure appropriate orientation of the bite bar using a level, and the subjects were visually monitored before and during the vibration exposure. For vertical seat vibration, the subject is exposed to three vibration magnitudes in both subject postures. The order of the presentation of the vibration magnitude for each posture is random for all subjects. The study involved about one hour of testing each day, and the duration of the testing for each vibration session lasted for three minutes. To avoid fatigue of the subjects, these short measurement sessions were always broken up by two-minute rest periods.

\subsection{Response Data Analysis}

Multifactor ANOVA has been performed using the SPSS software (SPSS Inc., Chicago, USA, V16) to verify the statistical significance level $(p<0.05)$ of the main factors upon the STHT responses. The main factors include the three excitation levels and the two sitting postures.

\section{RESULTS}

The mean STHT magnitude and phase responses for the three-axes of head motion with standard deviations of 30 subjects in both seated postures at $1.2 \mathrm{~m} / \mathrm{s}^{2}$ vibration magnitude during the Z-axis seat motion, is shown in Figs. 4 and 5. The effects of vibration magnitude on STHT are compared in Fig. 6. Similarly, the effects of subject postures are compared in Fig. 7. 


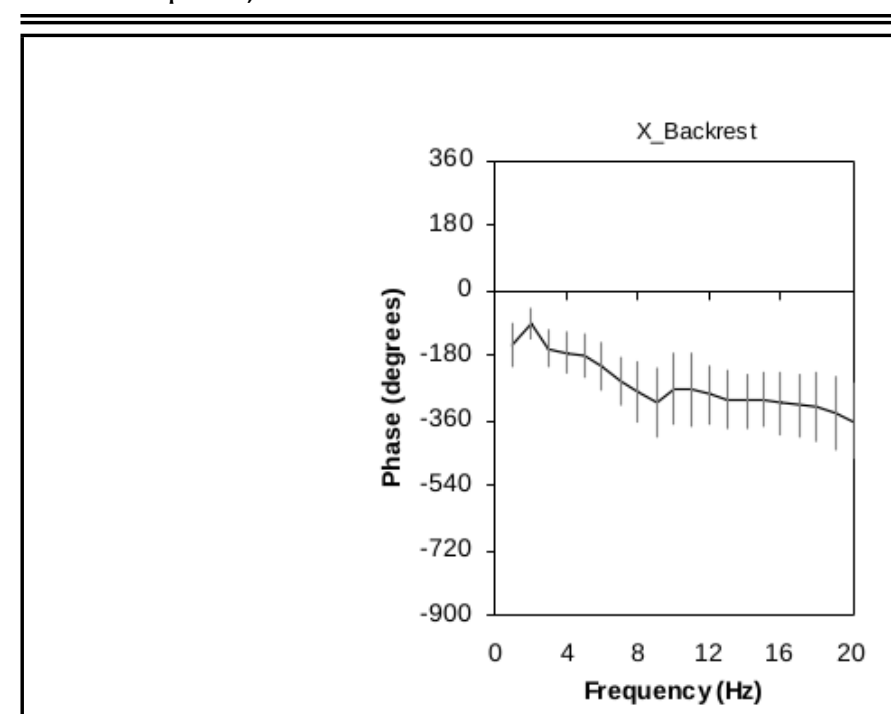

(a)

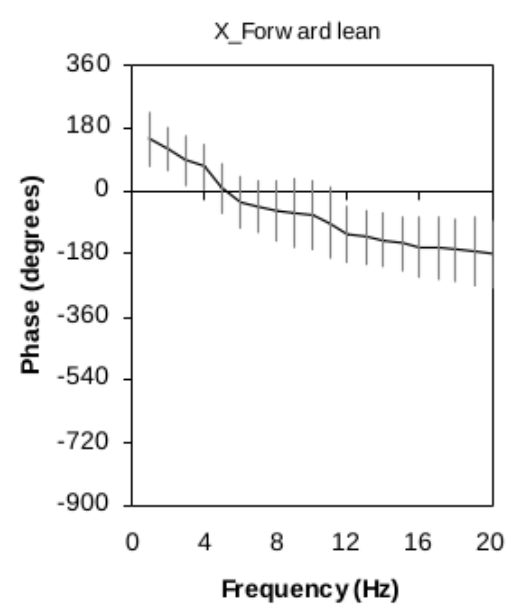

(c)

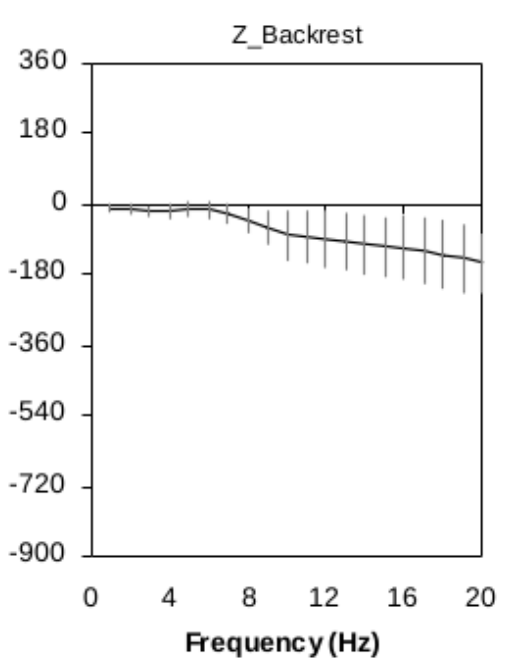

(b)

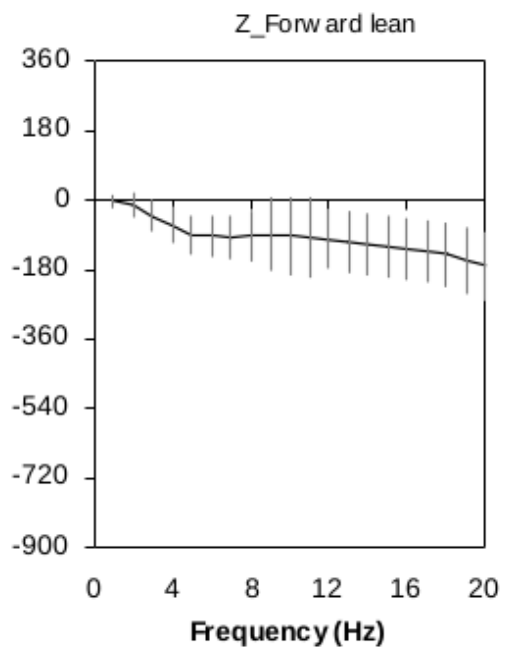

(d)

Figure 5. Phase curve with Z-axis seat vibration at $1.2 \mathrm{~m} / \mathrm{s} 2$ in the backrest posture for head motion on the X-axis (a), Z-axis (b), and forward-lean posture for head motion on the $\mathrm{X}$-axis (c), Z-axis (d).

\subsection{STHT Responses}

The mean STHT and phase curves for three directions of head motion of 30 subjects determined in two different postures, while exposed to $1.2 \mathrm{~m} / \mathrm{s}^{2} \mathrm{rms}$ acceleration in vertical seat vibration, are presented in Fig. 4 . The result shows that the single $\mathrm{Z}$-axis seat excitation resulted in head motion to both the $\mathrm{Z}$-axis and the $\mathrm{X}$-axis, irrespective of the subject postures. The STHT data acquired for the subjects show considerable scatter around the resonance frequency, while the magnitude peaks generally occur in a relatively narrow frequency band. Since most of the motion at the head occurred in the X- and Zaxis, only the phase data for these axes is presented in Fig. 5. The differences in phase between the two postures are small.

\subsubsection{Vertical In-Line STHT}

The transmissibility curve shows a gradual increase with frequency up to a resonance peak, followed by a gradual decrease in transmissibility with frequency, after about resonance peak in both the X-and Z-axis head motion. Despite considerable scatter between the STHT responses, the peak modulus oc- curred at $5 \mathrm{~Hz}$, often referred to as the primary resonance frequency of the seated body, irrespective of the subject's posture. The result shows that the mean vertical in-line STHT response reveals a peak magnitude near 1.86 in both postures.

\subsubsection{Fore-and-Aft Cross-Axis STHT}

It is observed in Fig. 4 (a) and (d) that the peak frequency in fore-and-aft cross-axis STHT appears similar to the resonance frequency evident in the in-line vertical STHT for the forward-lean posture. The result shows that the mean foreand-aft cross-axis STHT response reveals a peak magnitude of 2.05 at $5 \mathrm{~Hz}$ in the forward-lean posture and 1.94 at $4 \mathrm{~Hz}$ in the backrest posture.

\subsubsection{Lateral Cross-Axis STHT}

Figure 3 shows no clear resonance for Y-axis head motion in both subject postures. The forward-lean posture shows a small head motion up to $8 \mathrm{~Hz}$, and beyond that, negligible transmissibility is observed. 


\subsection{Effects of Vibration Magnitudes on STHT}

The mean STHT responses measured for the 30 subjects in both subject postures under vertical vibration magnitudes of $0.4,0.8$ and $1.2 \mathrm{~m} / \mathrm{s}^{2}$ are shown in Fig. 6 . As the magnitude of the vertical excitation increases from 0.4 to $1.2 \mathrm{~m} / \mathrm{s}^{2} \mathrm{rms}$, the principal resonance frequency decreases from $5 \mathrm{~Hz}$ to $4 \mathrm{~Hz}$ for $\mathrm{X}$-axis head motion and from $6 \mathrm{~Hz}$ to $5 \mathrm{~Hz}$ for Z-axis head motion. The results are found to be significant between 0.4 and $1.2 \mathrm{~m} / \mathrm{s}^{2}$, showing nonlinearity consistent with previous studies. ${ }^{1-3,6,13}$ This shift in the frequency, however, is more evident for the backrest posture.

Moreover, a small decrease in transmissibility at the resonance peak is found with increasing magnitude for both the $\mathrm{X}$ - and Z-axis head motion in the forward-lean posture, but a statistically insignificant difference was reckoned ( $p>0.05)$. For the Y-axis head motion in both subject postures, no notable difference is observed while varying vibration magnitudes $(p>0.05)$.

Figure 5 shows the comparison of the subject postures for each head motions, exposed to $1.2 \mathrm{~m} / \mathrm{s}^{2}$ vertical excitation. The STHT responses for both the postures exhibit similar trends in all the axes of head motion. The results clearly show that the forward-lean posture has significant influence on the vibration transmission through the upper body, compared to the backrest posture.

It is observed in the backrest posture for the X-axis head motion that there is a consistent reduction in transmissibility between the resonance frequency and frequencies up to $8 \mathrm{~Hz}$ $(p<0.05)$ and that above $8 \mathrm{~Hz}$, no significant difference was seen between postures $(p>0.05)$. Similarly, for the $\mathrm{Z}$-axis head motion, the peak frequencies remain nearly unchanged for both subject postures, whereas the transmissibility decreases significantly at the resonance peak for the backrest posture $(p<0.05)$. The result also explores the increase of transmissibility from $8 \mathrm{~Hz}$ up for the backrest posture, compared to the forward-lean posture $(p<0.05)$.

While comparing the transmissibility in both postures for Yaxis head motion, the transmissibility responses exhibit similar trends in both postural conditions. Although slight head motion was observed up to $8 \mathrm{~Hz}$ in the forward-lean posture, no statistical difference was seen between them $(p>0.05)$.

\section{DISCUSSION}

In the sitting posture, the vibration exciting the hip and thigh is transmitted to the head through the entire body. Thus, the vibration transmissibility to the head is essential to express the vibration characteristics of a body. Also, the vibration of the hip and the head is an important factor affecting the comfort, fatigue, and interference with activities due to visual disturbance.

The results for both the subject postures show that the single Z-axis seat excitation resulted in head motion in both the $\mathrm{Z}$ - and $\mathrm{X}$-axis, thus implying cross-coupling effect of vibration on head. Such interactions have been investigated at the back support only, by measuring the responses for both back support and non-back support in a few studies. ${ }^{27,28}$ Exposure to vertical vibration is also known to yield considerable fore-aft and pitch motions of the upper body, which are known to instigate considerable dynamic interactions with the back support. ${ }^{29}$

For the Z-axis head motion in both subject postures, the mean STHT showed a single peak at $5 \mathrm{~Hz}$, often referred to as the principal resonance frequency of the seated body. Similarly, for X-axis head motion, the mean STHT yielded a single peak at $4 \mathrm{~Hz}$ for the backrest posture and at $5 \mathrm{~Hz}$ for the forward-lean posture. The result is found to be consistent with previous findings for backrest posture. ${ }^{30,31}$ To understand the mechanism in which the resonance of the body occurs, Mansfield and Griffin measured both apparent mass and transmissibility during vertical excitation and found that vertical motion of the lumbar spine and pelvis showed resonances at about $4 \mathrm{~Hz}^{32}$ Matsumoto and Griffin investigated movement of the upper body of seated subjects exposed to vertical whole-body vibration at the principal resonance frequency and concluded that more than one vibration mode may contribute to the principal resonance in the apparent mass observed at about $5 \mathrm{~Hz}{ }^{33}$ If one assumes fatigue failure to be an important pathogenetic mechanism, ${ }^{34}$ and if one considers the static and dynamic strength of vertebrae, ${ }^{35}$ then the predicted forces can reach critical peak values, especially with a bent-forward posture.

Griefan et al. found the most disruption to reading due to the vibrations in the Z-axis at around 4-6 Hz, because of the elliptical movements of the head induced by the vertical oscillations. ${ }^{36}$ Griffin reported that higher difficulty in legible writing under vertical whole-body vibration observed in the range of 4 to $8 \mathrm{~Hz}$ could be attributed to the limb movements. ${ }^{17}$

As the magnitude of the $\mathrm{Z}$-axis excitation increased from 0.4 to $1.2 \mathrm{~m} / \mathrm{s}^{2}$, the principal resonance frequency decreased from $5 \mathrm{~Hz}$ to $4 \mathrm{~Hz}$ for $\mathrm{X}$-axis head motion and from $6 \mathrm{~Hz}$ to $5 \mathrm{~Hz}$ for the Z-axis head motion, with an added decrease in peak STHT. The results are found to be significant only between 0.4 and $1.2 \mathrm{~m} / \mathrm{s}^{2}$, showing nonlinearity consistent with previous studies. ${ }^{4,5,30,32,33}$ This shift in the frequency, however, is more evident for the backrest posture. This suggests that the upper body supported against a back support exhibits more of a softening tendency under a higher magnitude of vertical vibration as the musculoskeletal structure of the body has greater movement, which reduces its stiffness.

The effects of increase in excitation magnitude of singleaxis vibration, however, are not significant on the STHT responses of X-and Z-axis head motion for the forward-lean posture. Such effects are attributed to the subjects' tendencies to stiffen under greater upper- body motion caused by higher vibration magnitudes and to shift a greater portion of weight towards the legs to achieve a more stable sitting posture. . $^{50,37-39}$

The seated body supports (back and hand supports) tend to alter the upper-body movements and thus the biodynamic responses. The results reveal that the subject postures for $\mathrm{X}$ and Z-axis head motion have significant influence on vibration transmission through the upper body. It is observed that there is a consistent reduction in transmissibility for the $\mathrm{X}$ - axis head motion in the backrest posture between the resonance frequency and frequencies up to $8 \mathrm{~Hz}$, resulting in more of a 


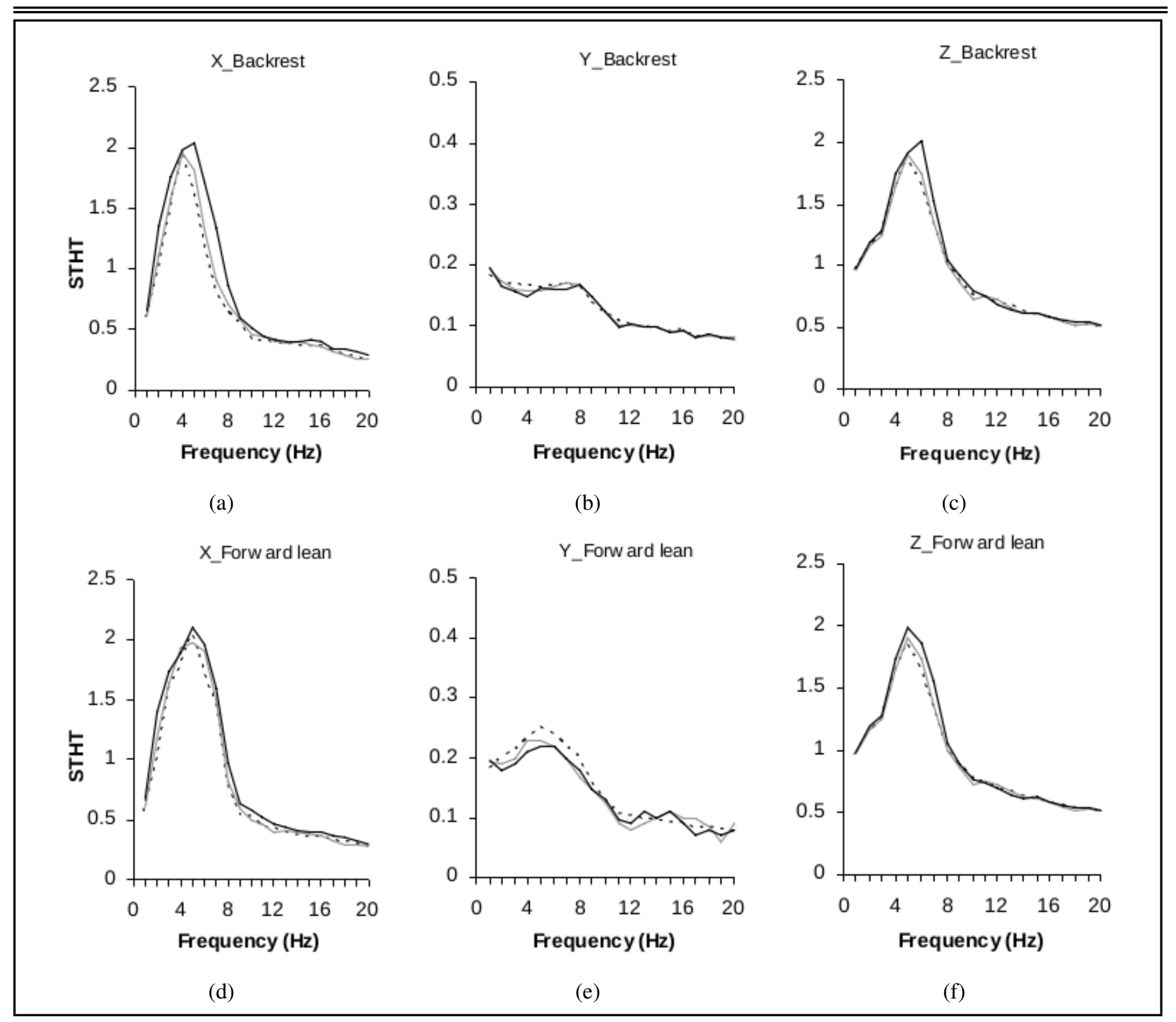

Figure 6. STHT curves with Z-axis seat vibration of three vibration magnitudes (- $0.4 \mathrm{~m} / \mathrm{s} 2,-0.8 \mathrm{~m} / \mathrm{s} 2$, and — $1.2 \mathrm{~m} / \mathrm{s} 2)$ in the backrest posture for head motion in the X-axis (a), the Y-axis (b), and the Z-axis (c); and the forward-lean posture for head motion in the X-axis (d), the Y-axis (e), and the Z-axis (f).

softening tendency. The results also reveal that the peak frequency remained nearly unchanged in both postures for the Zaxis head motion, whereas the transmissibility was decreased significantly around resonance peak for the backrest posture, resulting in a low transmission of motion to the head. It has also been suggested that placing the hands on the lap may help dampen the higher modes of vibration. ${ }^{33,40}$

The resonance peak in the forward-lean posture with hands on the table was more pronounced than that obtained in the backrest posture with hands in the lap. The vibrating hand support (table) would represent another source of vibration to the body or an additional driving point. The hands on the table are known to reduce the proportion of body weight on the seat pan and may cause a greater reaction force to the upper body. The combined effects of the forward-lean and hands support, which are more representative of the occupational passenger posture, might yield more pronounced effects on head motion.

\section{CONCLUSIONS}

The measured responses revealed that the single $\mathrm{Z}$-axis seat excitation resulted in head motion in both the Z- and the Xaxis. This cross-coupled motion was observed to be more pronounced in both subject postures. The cross-axis fore-aft and the vertical STHT responses showed a single resonance peak near $5 \mathrm{~Hz}$ regardless of the posture. An increase in the excitation magnitude consistently reveals a decrease in the response peak magnitude and the corresponding resonance frequencies, particularly in the presence of back support. This is attributable to the nonlinear softening effect in the muscle tension under the increasing intensity of vibration. However, an insignificant effect for the forward-lean posture is attributed to the subjects' tendencies to stiffen under greater upper-body motion caused by higher vibration magnitudes. The combined effect of the unsupported back and hands support, a representative sitting condition in a majority of the vehicles, was observed to be more pronounced around resonance peak in the forward-lean posture. 


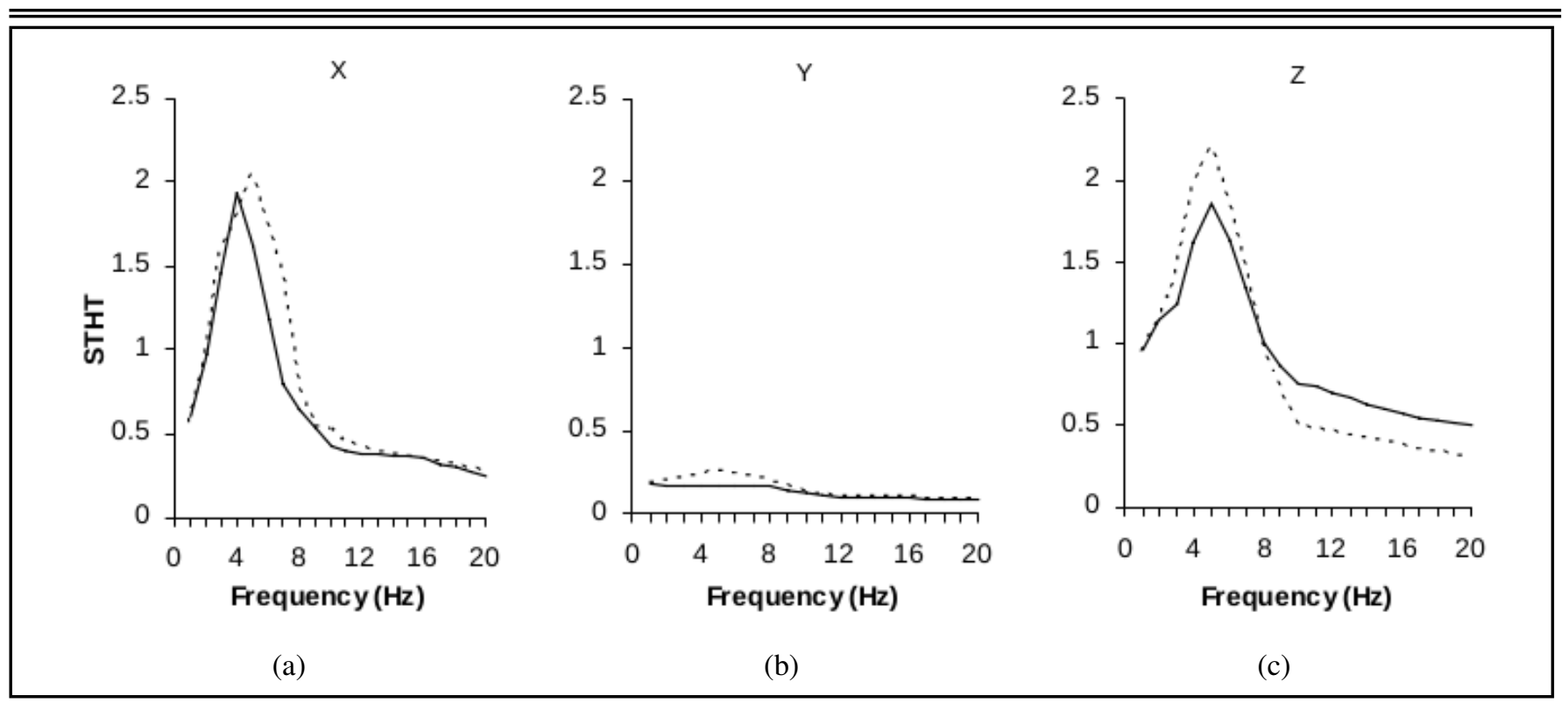

Figure 7. STHT curve with Z-axis seat motion of two postures (— - backrest; Z-axis (c).

\section{REFERENCES}

1 Coermann, R. R. The mechanical impedance of the human body in sitting and standing positions at low frequencies, Human Factors, 4, 227-253, (1962). https://dx.doi.org/10.1177\%2F001872086200400502

2 Miwa, T. Mechanical impedance of human body in various postures, Industrial Health, 13, 1-22, (1975). https://dx.doi.org/10.2486/indhealth.13.1

3 Vogt, H. L., Coermann, R. R. and Fost, H. D. Mechanical impedance of the sitting human under sustained acceleration, Aerospace Medicine, 39, 675-679, (1969). https://dx.doi.org/10.3951/sobim.31.17

4 Hinz, B. and Seidel, H. The non-linearity of the human body's dynamic response during sinusoidal wholebody vibration, Industrial Health, 25, 169-181, (1987). https://dx.doi.org/10.2486/indhealth.25.169

5 Fairley, T. E. and Griffin, M. J. The apparent mass of the seated human body: vertical vibration, Journal of Biomechanics, 22, 81-94, (1989). https://dx.doi.org/10.1016/0021-9290(89)90031-6

6 Lundstrom, R. and Holmlund, P. Absorption of energy during whole-body vibration exposure, Journal of Sound and Vibration, 215, 789-799, (1998). https://dx.doi.org/10.1006/jsvi.1998.1594

7 Holmlund, P., Lundström, R., and Lindberg, L. Mechanical impedance of the human body in vertical direction, Applied Ergonomics, 31, 415-422, (2000). https://dx.doi.org/10.1016/S0003-6870(99)00063-0

8 Mansfield, N. J. and Maeda, S. The apparent mass of the seated human exposed to single-axis and multi-axis wholebody vibration, Journal of Biomechanics, 40, 2543-2551, (2007). https://dx.doi.org/10.1016/j.jbiomech.2006.10.035
9 Paddan G. S. and Griffin, M. J. The transmission of translational seat vibration to the head - I. Vertical seat vibration, Journal of Biomechanics, 21, 191-197, (1988). https://dx.doi.org/10.1016/0021-9290(88)90169-8

10 International Organization for Standardization 5982, 2001. Mechanical vibration and shock-range of idealized values to characterize seated-body biodynamic response under vertical vibration.

11 Griffin, M. J., Lewis, C. H., Parsons, K. C. and Whitham, E. M. The biodynamic response of the human body and its application to standards, In: models and analogues for the evaluation of human biodynamic response, performance and protection, AGARD Conf. Proc. No. 253, (1979).

12 Newell, G. S. and Mansfield, N. J. Influence of posture and multi-axis vibration on reaction time performance and perceived workload, 41st United Kingdom Group Meeting on Human Responses to Vibration, Farnborough, Hampshire, England, (2006).

13 Rowlands, G. F., The transmission of vertical vibration to the heads and shoulders of seated men, Royal Aircraft Establishment, Report No. 77068, (1977).

14 Griffin, M. J. and Whitham, E. M. Individual variability and its effect on subjective and biodynamic response to whole-body vibration, Journal of Sound and Vibration, 58, 239-250, (1978). https://dx.doi.org/10.1016/S0022$460 \times(78) 80078-9$

15 Johnston, M. E., The effect of reclined seating on the transmission of linear vibration to the head, Royal Aircraft Establishment, Tech. Memo FS 292, (1979).

16 Lewis, C. H. and Griffin, M. J. Predicting the effects of vibration frequency, axis, and seating conditions on the reading of numeric displays, Ergonomics, 23, 485-499, (1980). https://dx.doi.org/10.1080/00140138008924762 
17 Griffin, M. J. Handbook of Human Vibration, 2nd Edition Academic Press, London, (2003).

18 Bhiwapurkar, M. K., Saran, V. H., Harsha, S. P. Objective and subjective responses of seated subjects while reading Hindi newspaper under multi axis whole-body vibration, International Journal of Industrial Ergonomics, 41, 625-633, (2011). https://dx.doi.org/10.1016/j.ergon.2011.06.004

19 Bhiwapurkar, M. K., Saran, V. H., Harsha, S. P., Goel, V. K., Berg, M. Effect of magnitudes and directions (monoaxis and multi-axis) of whole body-vibration exposures and subjects postures on the sketching performance, Proceedings of the Institution of Mechanical Engineers, Part F, Journal of Rail and Rapid Transit, 225 (1), 71-83, (2011). https://dx.doi.org/10.1243/09544097JRRT336

20 Vikas Kumar and Saran, V. H. Influence of reading format on reading activity under uniaxial whole body vibration, International Journal of Industrial Ergonomics, 44 (4), 520-527, (2014). https://dx.doi.org/10.1016/j.ergon.2014.05.004

21 Rutala, W. A. Manual of clinical microbiology, antisepsis, disinfection and sterilization in hospitals and related institutions, Washington DC: ASM Press, 227-45, (1996).

22 VanSickle, D. P., Cooper, R. A., Boninger, M. L. and DiGiovine, C. P. Analysis of vibrations induced during wheelchair propulsion, Journal of Rehabilitation Research and Development, 38, 409-421, (2001).

23 Paddan, G. S. and Griffin, M. J. A review of the transmission of translational seat vibration to the head, Journal of Sound and Vibration, 215, 863-882, (1998). https://dx.doi.org/10.1006/jsvi.1998.1592

24 Johnston, M. E. The effect of reclined seating on the transmission of linear vibration to the head, Royal Aircraft Establishment, Tech. Memo FS 292, (1979).

25 Barnes, G. R. and Rance, B. H. Head movement induced by angular oscillation of the body in the pitch and roll axes, Aviation, Space, and Environmental Medicine, 45, 987993, (1975).

26 Bendat, J. S. and Piersol, A. G. Random data-analysis and measurement procedures, Wiley, New York, (1992).

27 Hinz, B., Blüthner, R., Menzel, G., Rützel, S., Seidel, H., and Wölfel Horst, P. Apparent mass of seated men - determination with single- and multi-axis excitation at different magnitudes, Journal of Sound and Vibration, 298, 788-809, (2006). https://dx.doi.org/10.1016/j.jsv.2006.06.020

28 Sandover, J. and Dupuis, H. A reanalysis of spinal motion during vibration, Ergonomics, 30, 975-985, (1987). https://dx.doi.org/10.1080/00140138708969792

29 Donati, P. Survey of technical preventative measures to reduce whole-body effects when designing mobile machinery, Journal of Sound and Vibration, 253 (1), 169-183, (2002). https://dx.doi.org/10.1006/jsvi.2001.4254
30 Nawayseh, N. and Griffin, M. J. Tri-axial forces at the seat and backrest during whole-body fore-and-aft vibration, Journal of Sound and Vibration, 281, 921-942, (2005). https://dx.doi.org/10.1016/j.jsv.2004.02.047

31 Hinz, B., Menzel, G., Bluthner, R., and Seidel, H. Seatto-head transfer function of seated men-determination with single and three axis excitations at different magnitudes, Industrial Health, 48, 565-583, (2010). https://dx.doi.org/10.2486/indhealth.MSWBVI-03

32 Mansfield, N. J. and Griffin, M. J. Nonlinearities in apparent mass and transmissibility during exposure to whole-body vertical vibration, Journal of Biomechanics, 33, 933-941, (2000). https://dx.doi.org/10.1016/S00219290(00)00052-X

33 Matsumoto, Y. and Griffin, M. J. Movement of the upper body of seated subjects exposed to vertical whole-body at the principal resonance frequency, Journal of Sound Vibration, 215, 734-762, (1998). https://dx.doi.org/10.1006/jsvi.1998.1595

34 Sato, K. and Kikuchi, S. In vivo intradiscal pressure measurement in healthy individuals and in patients with ongoing back problems, Spine, 24, 2468-2474, (1999).

35 Seidel, H., Blugthner, R., Hinz, B. and Schust, M. On the health risk of the lumbar spine due to whole-body vibration - theoretical approach, experimental data and evaluation of whole-body vibration, Journal of Sound and vibration, 215, 723-741, (1998). https://dx.doi.org/10.1006/jsvi.1998.1601

36 Griefan, B., Brode, P. and Jaschinski, W. Contrast thresholds and fixation disparity during $5-\mathrm{Hz}$ sinusoidal and dual axis (vertical and lateral) whole body vibration, Ergonomics, 43, 317-332, (2000). https://dx.doi.org/10.1080/001401300184431

37 Fairley, T. E. and Griffin, M. J. The apparent mass of the seated human body in the fore-and-aft and lateral directions, Journal of Sound and Vibration, 139, 299-306, (1990). https://dx.doi.org/10.1016/0022-460X(90)90890-C

38 Mandapuram, S., Rakheja, S., Ma, S., and Demont, R. Influence of back support conditions on the apparent mass of seated occupants under horizontal vibration, Industrial Health, 43, 421-435, (2005). https://dx.doi.org/10.2486/indhealth.43.421

39 Wang, W., Rakheja, S. and Boileau, P-É. Effect of back support condition on seat to head transmissibilities of seated occupants under vertical vibration, Journal of Low Freq. Noise, Vibration and Active Control, 25 (4), 239-259, (2006). https://dx.doi.org/10.1260/026309206779884874

40 Vikas, K, and Saran, V. H. Influence of postures and vibration magnitude on seat-to-head transmissibility during uniaxial whole body vibration exposure, International Journal of Vehicle Noise and Vibration, 11 (2), 149-164, (2015). https://dx.doi.org/10.1504/IJVNV.2015.070026 